pregnancy. Serum of the infant in family 3 at birth had undetectable TBII and TSAb concentrations (table 1). We assume that the transient hypothyroidism in this infant was due to the suppression of secretion of thyroid stimulating hormone as the mother was hyperthyroid during the last half of her pregnancy.

\section{Discussion}

One of three unrelated infants born to mothers with hyperthyroidism developed transient neonatal hyperthyroidism. TBII and TSAb concentrations in the cord blood from this infant were high and almost the same as those in her mother during the third trimester of pregnancy. The other infant (family 2) who had high serum TSAb but normal TBII concentrations in the neonatal period did not develop hyperthyroidism and neither did the third infant (family 3) whose TBII and TSAb concentrations in the cord serum were both undetectable.

A recent study reported high concentrations of serum TBII in patients with transient neonatal hyperthyroidism but they did not measure TSAb concentrations. ${ }^{5}$ Another study showed that detectable TSAb in the mother in the third trimester was predictive for neonatal hyperthyroidism, but TBII concentrations were not measured. ${ }^{6}$

In our study TBII concentrations, but not those of TSAb, showed a good correlation with the development of neonatal hyperthyroidism and the concen- trations of TBII in the maternal sera during the third trimester of pregnancy might have predictive value in the neonatal hyperthyroidism. We think that widespread use of assays for both TBII and TSAb will clarify the pathogenesis and predictivity of transient neonatal hyperthyroidism.

\section{References}

1 Endo K, Kasagi K, Konishi J, et al. Detection and properties of TSH-binding inhibitor immunoglobulins in patients with Graves' disease and Hashimoto's thyroiditis. J Clin Endocrinol Metab 1978;46:734-9.

2 Onaya T, Kotani M, Yamada T, Ochi Y. New in vitro tests to detect the thyroid stimulator in sera from hyperthyroid patients by measuring colloid droplet formation and cyclic AMP in human thyroid slices. J Clin Endocrinol Metab 1973;36:859-66.

3 Shewring G, Smith BR; An improved radioreceptor assay for TSH receptor antibodies. Clin Endocrinol (Oxf) 1982;17: 409-17.

4 Kasagi K, Konishi J, Arai K, et al. A sensitive and practical assay for thyroid-stimulating antibodies using crude immunoglobulin fractions precipitated with polyethylene glycol. J Clin Endocrinol Metab 1986;62:855-62.

5 Teng CS, Tong TC, Hutchison JH, Yeung RTT. Thyroidstimulating immunoglobulins in neonatal Graves's disease. Arch Dis Child 1980;55:894-5.

6 Zakarija M, McKenzie M. Pregnancy-associated changes in the thyroid-stimulating antibody of Graves' disease and the relationship to neonatal hyperthyroidism. J Clin Endocrinol Metab 1983;57:1036-40.

Correspondence to Dr T Matsuda, Department of Paediatrics, Yonaha Hospital, Izumi, Kuwana, Mie, 511 Japan.

Received 7 August 1987

\title{
Severe combined immunodeficiency syndrome, tissue transplant, leukaemia, and $\mathrm{Q}$ fever
}

\author{
M M LOUDON AND E N THOMPSON
}

Department of Child Health, University of Wales College of Medicine, Cardiff, South Wales

SUMMARY A child born with severe combined immunodeficiency, who was immunoreconstituted by a fetal liver and thymus transplant, developed acute lymphoblastic leukaemia in the donor cell line. During remission she contracted acute $Q$ fever, which gave rise to unexpected complications. Early treatment of the $Q$ fever might have altered the subsequent events and prevented her death.

$Q$ fever is a sporadic infection and is an occupational hazard of men working with domestic sheep and cattle. The clinical features of the acute and chronic form in adults are well described. Reports in children are rare ${ }^{12}$ with less than 50 notifications from $1975-81 .{ }^{3}$ Heard et al reported five cases in immunocompromised adults. ${ }^{4}$ We describe a girl, who was 6 years old at the time of her death, who had been immunoreconstituted by transplantation with fetal liver and thymus at 9 months old because of severe combined immunodeficiency (SCID). Acute lymphoblastic leukaemia (ALL) subsequently developed in the donor cell line. During treatment she developed acute $Q$ fever from which she ultimately died. The advantage of co- 
trimoxazole prophylaxis in treatment against leukaemia is well known but its partial effectiveness in $\mathrm{Q}$ fever proved disadvantageous.

\section{Case Report}

Two girls, the only offspring of healthy parents, were born with SCID. The first died of graft versus host disease after an unrelated marrow transplant. The second child was successfully immunoreconstituted after a second fetal liver-thymic transplant at 9 months of age (the first had failed three months earlier). She remained well and asymptomatic for 21 months when she developed ALL (cALLA and Tdt positive) in the donor cells. At diagnosis the leucocyte count was $10 \cdot 1 \times 10^{9} / 1$, immunoglobulin concentrations were normal $(\operatorname{IgG} 7 \cdot 1 \mathrm{~g} / \mathrm{l}, \operatorname{IgA} 1.1 \mathrm{~g} / \mathrm{l}, \operatorname{IgM} 1.4 \mathrm{~g} / \mathrm{l})$; there was no organomegaly and the cerebrospinal fluid was not affected.

The Medical Research Council UKALL VIII B protocol was used for treatment. Induction drugs were daunorubicin, vincristine, asparaginase, and prednisolone. Cranial radiation and intrathecal methotrexate were used from week 6 to week 9. Cotrimoxazole $\left(150 \mathrm{mg} / \mathrm{m}^{2}\right)$ was used throughout the consolidation and maintenance phase. Despite the unusual history the chemotherapy was tolerated with no infection. Two years from diagnosis while on maintenance chemotherapy she developed an isolated meningeal relapse. This was treated with further intrathecal methotrexate and craniospinal irradiation and the leukaemia induction repeated. Co-trimoxazole prophylaxis was stopped.

Four weeks later she became acutely ill with a high intermittent fever, severe headache, photophobia, myalgic pain in the neck and chest, sore throat, dry cough, and noticeable irritability. A florid centripetal haemorrhagic maculopapular rash appeared. Blood count initially was normal, but fell to $0: 5 \times 10^{9} / 1$ with an appreciable lymphocytosis by day 5. Mild hepatocellular disturbance was noted. A chest $x$ ray film was clear. Cerebrospinal fluid examination gave normal results. No significant bacterial or viral isolates were found and a battery of viral titres, mycoplasma titres, and Weil Felix reaction all gave normal results.

After a variety of empirical antibiotic treatments she slowly improved. Co-trimoxazole and maintenance chemotherapy were restarted. Retrospectively, a diagnosis of $Q$ fever was made as the phase II titre peaked (1/512) six weeks later. No specific treatment was given as she was asymptomatic, although the raised titre persisted. Nine months later she developed vomiting, headache, fits, and hemiparesis. Extensive investigations including examination of the cerebrospinal fluid and computed tomography failed to identify a cause. She was treated with dexamethasone and anticonvulsants as it was assumed she had developed leukoencephalopathy after her previous treatment of the central nervous system. All treatment including co-trimoxazole was stopped. Three weeks later she developed a further exacerbation of the acute influenzal like illness with the central nervous system being affected. Chronic $\mathbf{Q}$ fever was suspected despite a normal echocardiogram and no increase in phase 1 titre. Intravenous tetracycline (continued orally for four months) resulted in a complete and rapid recovery with immediate resolution of phase II titre. Three months later, there was a leukaemic marrow relapse from which she subsequently died a month before her 6th birthday. No further illness attributable to $Q$ fever had occurred.

\section{Discussion}

The clinical course of this child's illness was punctuated by three separate events, which were apparently unrelated. Successful immunoreconstitution of SCID with a matched bone marrow donor or a fetal liver and thymus transplant in those without a donor has been recorded. ${ }^{5}$ Prompt restoration and maintenance of immune function after the second fetal liver and thymic transplant was present throughout the preleukaemic and leukaemic phase of our patient's life. The development of ALL in the donor male cells, presumably of fetal origin, has never been previously described. The subsequent course of the leukaemia with a meningeal relapse and ultimately a marrow relapse was perhaps more aggressive than might have been predicted from the presenting (standard risk) features. Optimum chemotherapy doses, however, were well tolerated by the patient's marrow, with no increase in susceptibility to infection until the episode of $Q$ fever.

The unusual features of the $Q$ fever and its chronicity probably occurred as a result of immunosuppressive treatment and partial suppression by cotrimoxazole. The rapid response to intravenous tetracycline and serological conversion can be taken as diagnostic evidence of $\mathrm{Q}$ fever infection. The source of the infection was unknown, although an outbreak in the county had been reported four years earlier. ${ }^{6}$ Neither parent, however, had a similar illness or raised titre. Blood products have been suggested as a source of infection, but this child had only received one unit of blood three years earlier. Although $Q$ fever is rare, it is not difficult to diagnose or confirm. With hindsight, we should 
have given appropriate treatment earlier because of the persistently high titre. Early adequate treatment might have permitted continuation of antileukaemia maintenance that might have prevented the subsequent marrow relapse that resulted in her death.

We would like to thank Professor John Barrett, department of haematology, Westminster Hospital, London who performed the fetal transplant and gave helpful advice in the preparation of this manuscript. We also thank Dr Jean-Louis Touraine, Hopital Edouard Herriot, Lyon, France for supplying fetal transplant tissuc, and Dr Julie Munro, department of virology, University Hospital of Wales for help with the virological investigations.

\section{References}

1 Tonge JI, O'Reily MJS. Davison A, Brown HE. “ $Q$ " Fever. Annual Report of the Health and Medical Services, Queensland 1959-60. 1960:109.
2 Turck WPG. "Q" Fever. In: Brande AI, Davis CE, Fiever J, eds. Medical microbiology and infectious diseases. London: WB Saunders. 1981:932-7.

${ }^{3}$ Palmer SR, Young SEJ. "Q" Fever endocarditis in England and Wales 1975-81. Lancet 1982;ii:1448-9.

${ }^{4}$ Heard SR, Ronalds CJ, Heath RB. Coxiella burnetti infection in immunocompromised patients. $J$ Infect 1985;ii:15-8.

5 Touraine JL, Roncarolo GL, Marseglia G, et al. Fetal liver transplantation in immunodeficiencies and inborn errors of metabolism. In: Gale RP, Touraine JL, Lucarelli G, eds. Fetal liver transplantation. New York: Alan R Liss, 1985:299-313.

6 Salmon MM, Howells B, Glencross EJG, Evans AD, Palmer SR. "Q" Fever in an urban area. Lancet 1982;i:1002-4.

Correspondence to $\mathrm{Dr}$ EN Thompson, Department of Child Health, Llandough Hospital, Penarth, South Glamorgan CF6 $1 \mathrm{XX}$.

Received 16 September 1987

\title{
Giving assessment reports to parents
}

\author{
H McCONACHIE, S LINGAM, B STIFF, AND K S HOLT \\ Wolfson Centre, Institute of Child Health, London
}

SUMMARY Reactions of 25 parents to receiving copies of written reports concerning developmental assessment of their children were assessed. All parents wanted to have a written report.

The implementation of the 1981 Education Act has meant that parents now receive a copy of all the assessment documents that contribute toward a statement of their child's special educational needs. Parents also have a right to contribute written evidence of their own about the child. They thus need full information about their child's development.

At the Wolfson Centre children with complex developmental problems are assessed by a multidisciplinary team. After the assessment a full discussion of findings is held with the parents by members of the team. A report is then sent to the referring doctor, and with parent's permission, a copy to other relevant professionals. In general, the practice has been to give a copy of the report to parents only when they request it.

The advantages and possible difficulties of giving a written assessment report to the parents of children with developmental problems have been discussed previously. ${ }^{2}$ It has been found that written reports are popular with parents. Similar positive responses have been found when general medical patients have been given copies of hospital clinic letters sent to the general practitioner. ${ }^{3}$ In the light of these experiences it was decided to conduct a small evaluation study of routinely sending written assessment reports to parents.

\section{Subjects and methods}

Twenty five children seen consecutively by one of the paediatricians (SL) were included. The children's mean age was 5 years 8 months (range 7 months to 11 years 6 months). Their primary diagnostic categories included delayed development (8 children), cerebral palsy (6), speech or language disorder, or both (5), educational difficulties (4), and hyperactivity (2). Most presented a complex picture of disability.

Parents received the same report as was sent to professionals. For 10 children the assessment was conducted primarily by the paediatrician and the report prepared by him alone. For four children the report was written jointly by the paediatrician and a therapist, and for 11 others the paediatrician and the psychologist or therapist, or both, wrote reports separately. In all cases the professional knew the report would be sent to the parents.

Parents were interviewed about their reactions to the report(s), by either HM on the telephone, or the child's health visitor (six cases). Questions were asked about how comprehensible and useful the reports seemed, and also whether they reflected accurately what the parents remembered of the 